\title{
Reduction of NOx emission \& Performance characteristics of Waste Cooking Oil from diesel engine using Exhaust gas Recirculation
}

\author{
M. A. Khote* and P. A. Deshmukh \\ Rajarshi Shahu College of Engineering, Tathawade,SP Pune University, Mumbai, India
}

Accepted 15 June 2016, Available online 20 June 2016, Special Issue-5 (June 2016)

\begin{abstract}
For transportation \& mechanized Agricultural equipments, IC engine play as vital role in real life. So the consumption of diesel and petroleum is upsurged. India having heavy population, lots of waste cooking oil is wasted. If Waste cooking oil is used as biodiesel for alternative source of diesel, as diesel \& petroleum are non conventional source of energy. Exhaust gas emitted from compression ignition (C.I.) engine is a mixture of many undesirable constituents known as pollutants like oxides of nitrogen (NOx), $\mathrm{HC}, \mathrm{CO}$, etc.. In this paper we are going to investigate emission and performance characteristics of waste cooking oil from diesel engine using Exhaust Gas Recirculation (EGR). EGR is a technique reducing the oxides of nitrogen (NOx) emission from diesel engine. A Single cylinder, water cooled, constant speed direct injection diesel engine was used for this experiment. The graphs were plotted comparing the emissions from diesel fuel and Waste cooking oil biodiesel fuel without EGR and with 5\%, 10\%, 15\% EGR.
\end{abstract}

Keywords: Waste Cooking Oil, Biodiesel, EGR, Emission, D I Diesel Engine

\section{Introduction}

In India because of large amount of population and availability of large number of restaurants a huge amount of edible oil is used for food preparation. The used oil thus produced is dumped outside resulting in environmental degradation. This could be avoided if these used waste cooking oils are collected and converted into biodiesel. In this study used palm oil was collected from different restaurants \& smacks centers from region of Maharashtra and was converted into biodiesel. The biodiesel thus produced is blended with diesel at different volume proportions and tested in a DI diesel engine to evaluate its performance, emission and combustion profile.

Bio diesel, produced from different vegetable oils (soybean, rapeseed and sunflower etc.), have been used in internal combustion engines without major changes, with only slightly less performance.

Vegetable oils having higher viscosity because huge carbon deposits can be used only as a short term fuel in diesel engines. Viscosity of vegetable oils can be reduced and made equivalent to diesel fuel by transetherification. Large number of feedstock including non-edible oils and wastes from hotels, beef tallow and chicken feather meals are utilized for biodiesel production. In developed countries, used cooking oils are available in plenty and are used as cheap feedstock for biodiesel production.
In Taiwan, millions of tons of vegetable oil are discarded as waste cooking oil each year, and a large amount is flushed down the drain, which is also the main cause of river pollution. Using waste cooking oil to produce biodiesel could prevent pollution to rivers, lakes, and sea, reduce the air pollution caused by fossil fuels, such as CO2 emissions, and lessen the high dependence on fossil fuels (Yung-Sung Lin et al, 2010).

The use of biodiesel resulted in lower emissions of total hydrocarbon (THC) and CO, and increased emissions of NOx (Ridvan Arslan, 2011). One efficient method to control NOx in order to achieve the future emission limit is the rather high exhaust gas recirculation (EGR) rates accompanied by increased boost pressure to avoid the negative impact on soot emissions. EGR is one of the most effective means of reducing $\mathrm{NOx}$ emissions from compression ignition (CI) engines and is widely used in order to meet the emission standards (Mastaqim Bin Mohamad, 2010).

The effect of biodiesel addition on the regulated emissions, particulate number size distribution and mass concentration, as well as the particulate oxidation characteristics have been studied at five engine loads at a constant engine speed of 1800rpm. Generally, biodiesel leads to a reduction of $\mathrm{HC}, \mathrm{CO}$ and particulate mass concentrations and particle number concentrations but an increase in NOx. Moreover, particulate soot generated from biodiesel has more volatiles and is easier to be burned off than diesel soot (C.S. Cheung, 2015). 
Methyl esters of Punnai, neem, and waste cooking oil can be directly used as fuel for diesel engine in the pure form (B100) without much modification for short-term only, because there is a drastic increase in smoke emission as compared to diesel fuel. Overall, the methyl esters of waste cooking oil proved improvements in performance and emission characteristics than the methyl esters of Punnai and Neem due to its closer physical and thermochemical properties to neat diesel (D. Subramaniam et al, 2013).

\section{Material \& Method}

Waste cooking oil collected from the restaurants is considered as feedstock for the biodiesel production. Transesterification is a chemical process of transforming large, branched, triglyceride molecules of Waste cooking oils and fats into smaller, straight chain molecules, almost similar in size to the molecules of the species present in diesel fuel.

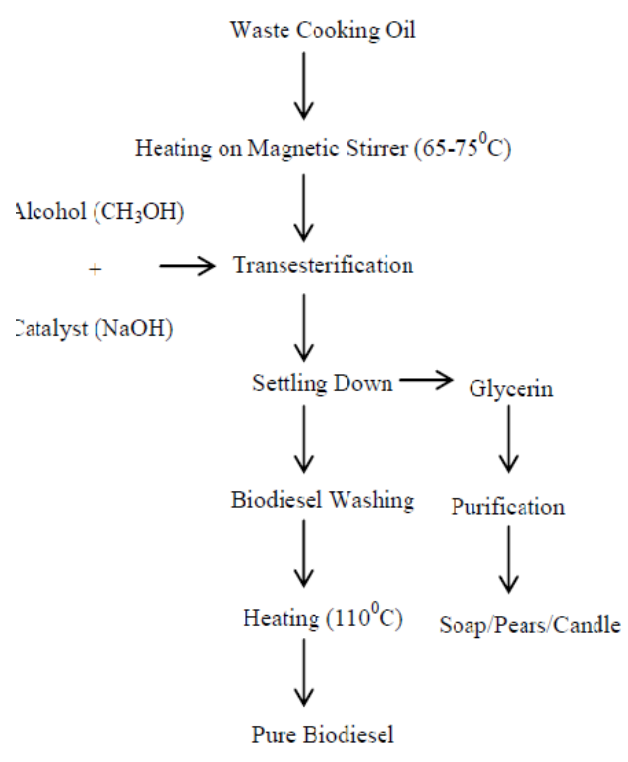

Fig 1 Flow Chart of Biodiesel Production Process

The process takes place by reacting the vegetable oil with an alcohol in the presence of catalyst. In general, due to high value of free fatty acids (FFA) of waste vegetable oils, acid catalyzed transesterification is adopted. However, FFA of the feedstock used in this work is less and hence alkali catalyzed transesterification process is employed for the conversion of Waste cooking oil into ester. The Waste cooking oil is preheated in a reactor to remove the moisture. Potassium methoxide is prepared by dissolving potassium hydroxide in methanol. Various concentration of $\mathrm{KOH}$ in the methoxide was prepared and the process is optimized for the maximum yield. For the optimized $\mathrm{KOH}$ concentration, alcohol proportion also optimized to obtain the maximum yield. Methoxide is mixed with preheated oil and the reaction carried out under nominal speed stirring by a mechanized stirrer and at a constant reaction temperature of $55^{\circ} \mathrm{C}$ for 2 hours. During that time period the chemical reaction takes place between raw WCO oil and the methanol. At the end of completion of reaction, the mixture was drained and transferred to the separating funnel. The phase separation was taken place in the funnel in two layers. Upper layer was the biodiesel and lower phase was Glycerine. Finally, washing was made with water.

Table 1 Properties of Oil

\begin{tabular}{|c|c|c|c|}
\hline Sr. No. & Property & Diesel & WCO \\
\hline 1 & Density $(\mathrm{kg} / \mathrm{m} 3)$ & 850 & 885 \\
\hline 2 & Kinematic Viscosity $(\mathrm{cSt})$ & 2.44 & 4.76 \\
\hline 3 & Heating Value & 41000 & 40800 \\
\hline 4 & Could Point $\left({ }^{\circ} \mathrm{C}\right)$ & 3 & 16 \\
\hline 5 & Pour Point $\left({ }^{\circ} \mathrm{C}\right)$ & -6 & 19 \\
\hline 6 & Flash Point $\left({ }^{\circ} \mathrm{C}\right)$ & 70 & 145 \\
\hline
\end{tabular}

\section{Experimental Setup}

A Single cylinder, water cooled, constant speed directinjection diesel engine fuled with diesel fuel \& mixed concentration of biodiesel is selected for experimentation. The mixed concentration contains including pure diesel fuel, B10 (fuel containing 10\% of biodiesel), B20, B30. Also some modification made into this engine for exhaust gas recirculation (EGR). To cool the exhaust gases while entering in the inlet to engine, heat exchanger is used. Control valve is also provided to re-circulate the required percentage of exhaust gases passed to the inlet to the engine. Table 1 shows the characteristics of biodiesel. To the reading of emission smoke meter is used.

The concentration of emission measured when the engine attains steady state for each set of readings. The schematic of experimental set up is shown in figure 2 .

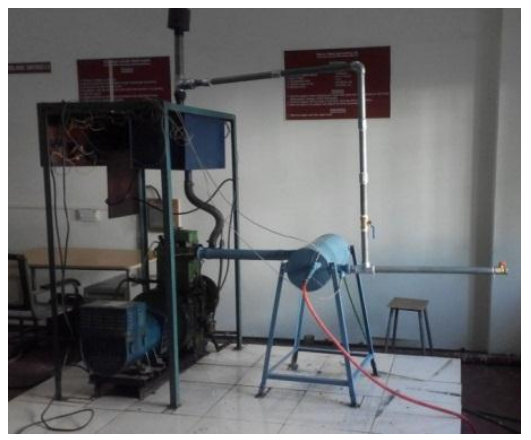

Fig. 2 Experimental setup engine with EGR

Specifications of diesel engine are shown in table 2 . The engine is running on five different loads like 0 , $200,400,600,800$ with 5\%,10\% \& 15\% EGR.

Table 2 Engine Specifications

\begin{tabular}{|c|c|c|}
\hline Sr. No. & Specification & Value \\
\hline 1 & Type & Single Cylinder \\
\hline 2 & Maximum Engine Output & $3.7 \mathrm{kw}$ \\
\hline 3 & Maximum Engine Speed & $1500 \mathrm{rpm}$ \\
\hline 4 & Bore x Stroke & $87 \times 110 \mathrm{~mm}$ \\
\hline 5 & Compression Ratio & $16: 1$ \\
\hline
\end{tabular}


All gas concentrations of emission were continuously recorded for more than 5 minutes and the average results were presented in this paper. Each reading was repeated twice and the results were found to agree with each other at $90 \%$ confidence level.

\section{Result \& Discussion}

The nature of variation of Carbon Monoxide (CO) with Brake Power is shown in Fig. 3. At lower loads on engine is operated at higher air fuel ratios, ultimately these lean mixtures left unburnt leads to higher $\mathrm{CO}$ emissions. At higher Brake power rich mixtures leads to increase in CO formation. CO emissions increases with EGR rate at a given load of engine operation.

Fig. 3 shows detailed variation of $\mathrm{CO}$ emission for pure diesel fuel, B10, B20 \& B30. In comparison with this blends the $\mathrm{B} 30$ having less emission of $\mathrm{CO}$.

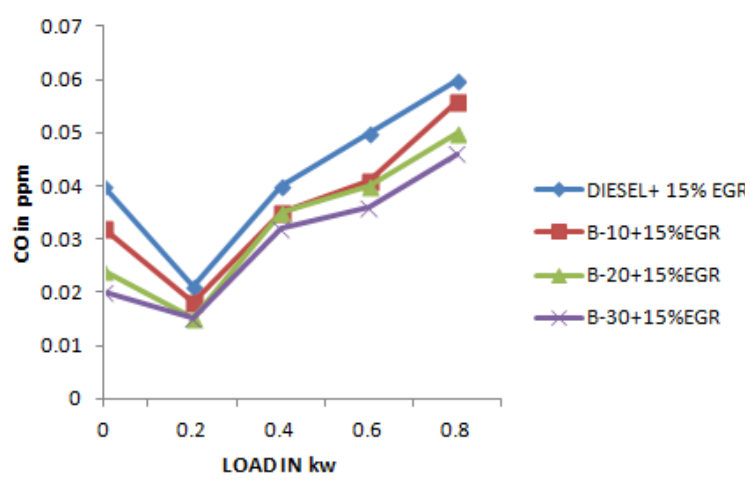

Fig. 3 Variation of CO with Load in kw

The effect of exhaust gas recirculation on $\mathrm{CO}$ emissions is shown in figure 4. CO emissions increases with EGR rate at a given load of engine operation.

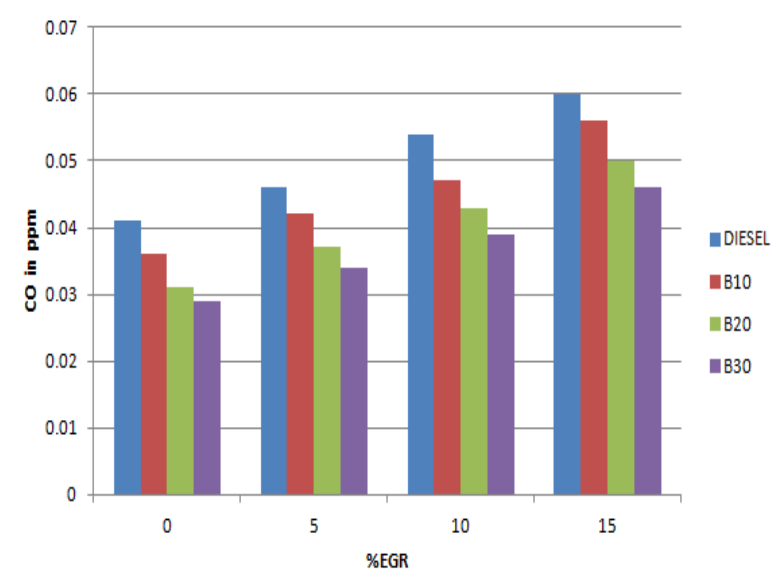

Fig. 4 Variation of CO Vs. EGR

Nitrous oxide formation is a temperature dependant phenomenon along with residence time of fuel and air. Biodiesel combustion emits more NOx in comparison to diesel. The reason can be due to quantity of nitrogen present in the fuel. Figure 4 gives the variation of NO with load. It is evident that as the load increases NO emissions increased, due to rise in temperature leads to more NO formation. NOx emissions versus EGR rate at full load is shown in figure 5. NOx is found highest for B-30 and decreased with increase in EGR percentage.

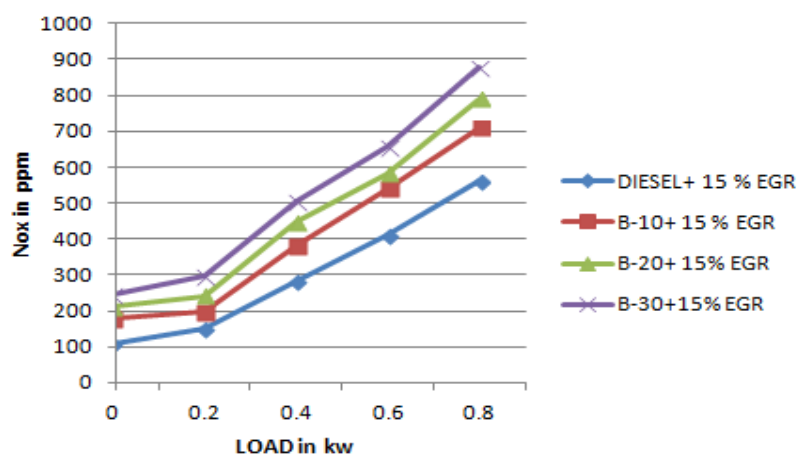

Fig.4 Variation of NOx with load in kw

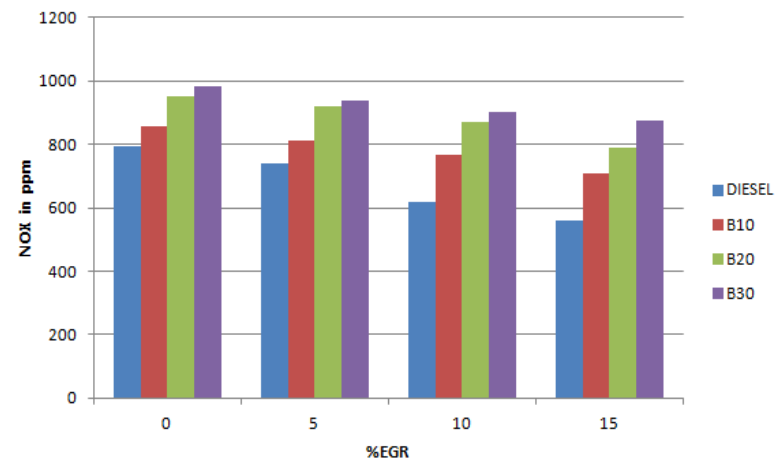

Fig. 5 Variation of NOx vs. EGR \%

It is observed that as EGR rate increases a rise Unburnt HC emission occurred in the exhaust.UHC emissions are lower for biodiesel diesel blends and with pure biodiesel the quantities are much reduced in comparison to diesel for all the loads of engine operation. Effect of EGR is to increase the HC emissions in the exhaust. Pure diesel observed to be giving higher UHC emissions with EGR rate in comparison to biodiesel. Variation in HC for Diesel and Blends with change in EGR rate is as shown in fig. 6

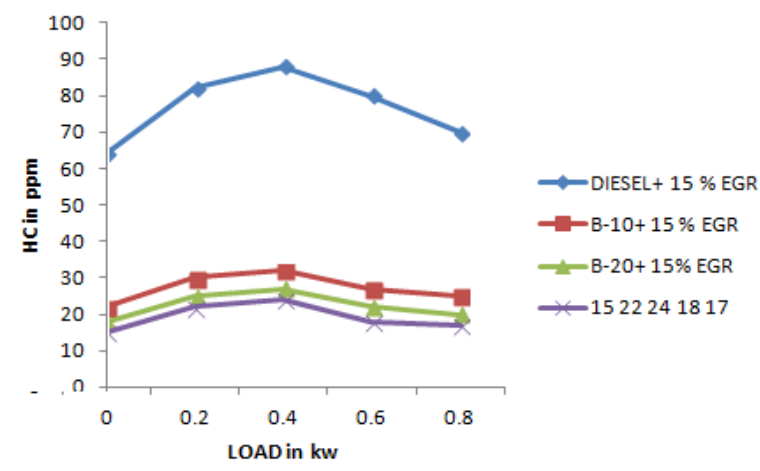

Fig, 6 Variation of HC with Load in kw 


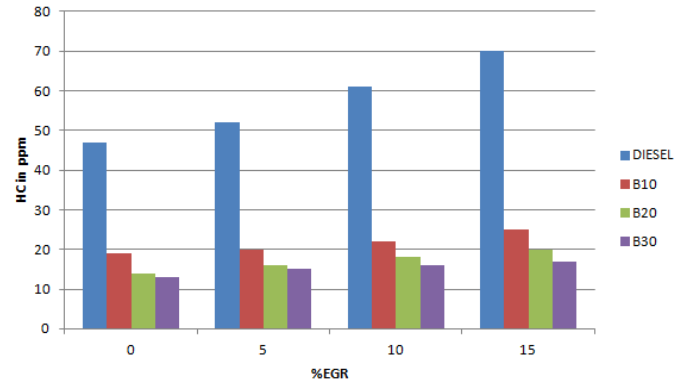

Fig. 7 Variation in HC Vs. EGR \%

BSFC variation with EGR rate at full load is shown in figure 8. With the rise in EGR rate there is, rise specific fuel consumption this is severe for higher EGR rates i.e. more than $20 \%$. The engine was run with EGR at the cost of little fuel loss.

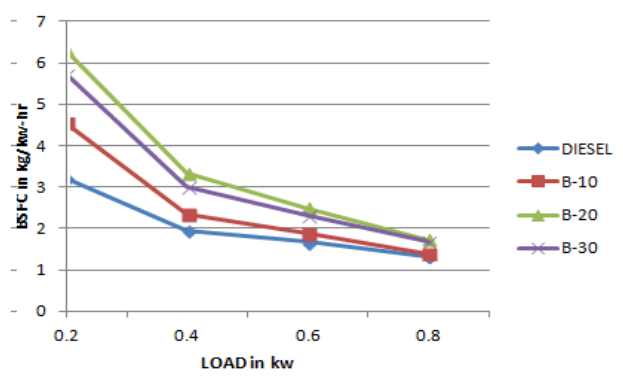

Fig. 8 Variation BSFC in $k g /(k w-h r)$ Vs. Load in kw

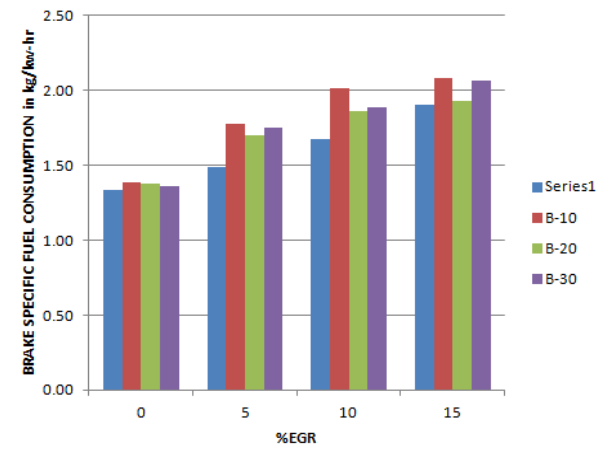

Fig. 9 Variation of BSFC Vs \% EGR

The graph of variation in Brake thermal efficiency for Diesel, B10, B20 and B30 Vs Load in kw is shown in fig 10. There is a rise in thermal efficiency with B10, B20 when compared with pure diesel.

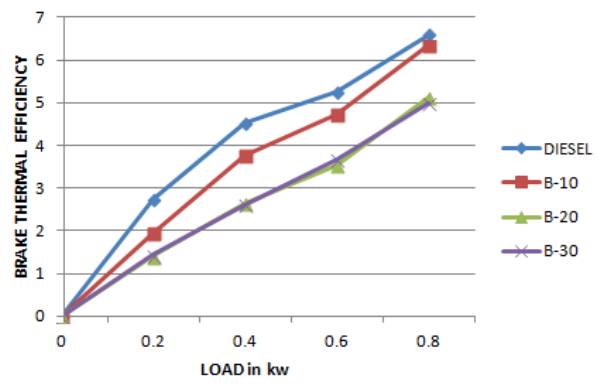

Fig. 10 Variation BTE $k g /(k w-h r)$ Vs. load in kw
It is found that with increase in EGR rate, there is decrease in BTE. Variation of BTE Vs \% EGR is as shown in fig. 11

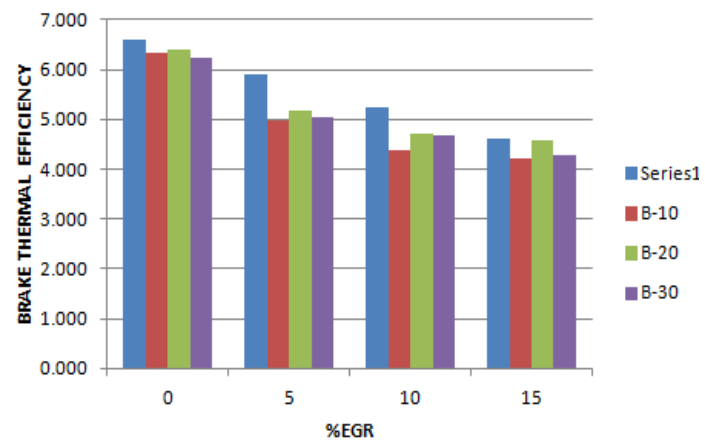

Fig. 11 Variation of BTE Vs. EGR \%

The graph of variation in Mechanical efficiency for Diesel, B10, B20, and B30 Vs Load in KW is shown in fig. 12. It is found that mechanical efficiency for B10, $\mathrm{B} 20$, and B30 is almost constant.

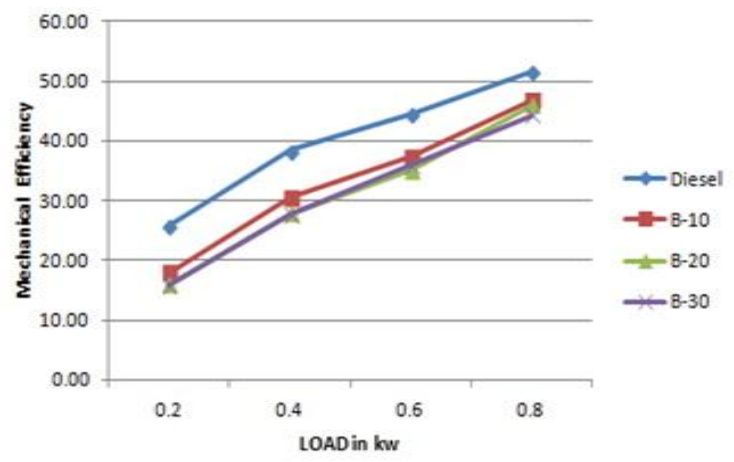

Fig. 12 Variation in Mechanical efficiency Vs. load

\section{Conclusions}

1) For pure biodiesel Brake Specific fuel consumption increases and decreases for B10 \& B20 in comparison with diesel. The main reason of increase in BSFC values for pure biodiesel its high value of viscosity when compared with diesel.

2) NOx emissions are considerably reduced with the rise in EGR rate. When the engine is operated with biodiesel EGR would be best pre treatment method to reduce the NOx emissions at the cost of little fuel penalty.

3) Unburnt hydrocarbon emissions seem to reduce with Biodiesel-diesel blends and with pure biodiesel, however with EGR the hydrocarbon emissions increased. With increase in EGR rate the carbon monoxide emissions also increased.

\section{Acknowledgment}

I take this opportunity to express my deep sense of gratitude to my guide \& PG Co-Ordinator, Dr. P. A. Deshmukh. I would like to convey my sincere thanks to him for his consistent help, valuable guidance, 
scholarly encouragement, selflessness time investment and thought provoking discussions which inspired me to make this report fruitful. I would like to thank Dr. M. S. Deshmukh for his help and valuable suggestions during this work. I am grateful to Dr. A.A. Pawar, Head of Mechanical Engineering Department for his valuable suggestions.

I would like to express my deepest sense of gratitude to respected Principal Dr. D.S. Bormane, for providing us basic infrastructure and other facilities.

\section{References}

H. An, W.M. Yang, A. Maghbouli, J. Li, S.K. Chou, K.J. Chua, (2013), Performance, combustion and emission characteristics of biodiesel derived from waste cooking oils, ELSEVIER, 112, 493-499.

Ridvan Arslan, (2011), Emission characteristics of a diesel engine using waste cooking oil as biodiesel fuel, African Journal of Biotechnology, 10 (19), pp.3790-3794

H. Sharon, K. Karuppasamy, D. R. Soban Kumar, A Sundaresan, (2012), A test on DI diesel engine fueled with methyl esters of used palm oil, ELSEVIER, 47, 160-166.

C.S. Cheung, X.J. Man, K.W. Fong, O.K. Tsang, (2015), Effect of waste cooking oil biodiesel on the emissions of a diesel engine, ELSEVIER, 66, 93-96.
D. Subramaniam, A. Murugesan, A. Avinash, (2013), A comparative estimation of C.I. engine fuelled with methyl esters of punnai, neem and waste cooking oil, International Journal of Energy And Environment, Vol. 4, pp.859-870.

Jagannath Balasaheb Hirkude, Atul S. Padalkar, (2012), Performance and emission analysis of a compression ignition

Engine operated on waste fried oil methyl esters, ELSEVIER, 90, 68-72.

K. Nantha Gopal, Arindam Pal, Sumit Sharma, Charan Samanchi, K. Sathyanarayanan, T. Elango, (2014), Investigation of emissions and combustion characteristics of a CI engine fueled with waste cooking oil methyl ester and diesel blends, Alexandria Engineering Journal, 53, 281287.

Jaffar Hussain, K. Palaniradja, N. Alagumurthi, R. Manimaran, (2012), Effect of Exhaust Gas Recirculation (EGR) on Performance and Emission characteristics of a Three Cylinder Direct Injection Compression Ignition Engine, Alexandria Engineering Journal, 51, 241-247.

H.E. Saleh, (2009), Effect of exhaust gas recirculation on diesel engine nitrogen oxide reduction operating with jojoba methyl ester, Renewable Energy, 34, 2178-218.

Magin Lapuerta, Octavio Armas, Jose Rodriguez-Fernandez, (2008), Effect of biodiesel fuels on diesel engine emissions, Progress in Energy and Combustion Science, 34, 198-223. 